\title{
Multiloop Control Strategy for Grid-Interfaced Three-Phase Voltage Source Inverter with Passively Damped LLCL-Filter
}

\author{
H. Azani ${ }^{1,2}$, A. Massoud ${ }^{1}$, senior member, IEEE, L. Ben-Brahim ${ }^{1}$, senior member, IEEE, \\ B. W. Williams ${ }^{2}$, and D. Holliday ${ }^{2}$ \\ ${ }^{1}$ Qatar University -Electrical Engineering Department, \\ ${ }^{2}$ Strathclyde University - Electronics and Electrical Engineering Department
}

Keywords: LLCL filter, Passive damping, Multiloop control strategy, Proportional-Integral (PI) controller, ProportionalResonant (PR) controller

\begin{abstract}
In inverter-based distributed generation (IBDG) and similar to the conventional third order LCL filter, the high order LLCL filter is difficult to stabilize, and may cause a resonance between the inverter and the grid. Passive damping techniques were explored in literature by connecting a resistor in different locations of the LLCL filter. This paper presents the performance of the high-order LLCL-filter with RC passive damping circuit through evaluating the system stability using dual-loop control strategy that has been applied to the LCLfilter. Comparative analysis regarding PI and PR controllers used in the proposed control strategy is offered. Simulation results using Matlab are conducted, presented, and discussed.
\end{abstract}

\section{Introduction}

Renewable energy sources mostly necessitate power electronic converters in order to comply with the grid voltage and frequency requirements. Grid integration of voltage source inverters (VSIs) requires a passive filter between the VSI and the grid for harmonic mitigation. The first-order L filter reduces harmonics generated by the converters but at the expense of high inverter switching frequency with bulky and expensive filter inductor. For better performance, the second-order LC filter can be employed. The most common solution is to use the third-order LCL filter VSI. The LCL-filter reduces the filter size and introduces better dynamics and attenuation of switching harmonics compared to a simple L filter. However, the LCL filter is difficult to stabilize in closed loop operation, and may cause a resonance between the grid and the inverter. Therefore, passive damping or active damping are the solutions to these problems. Many studies were conducted on these types of damping approaches such as adding a resistor to the capacitor branch for LCL filter damped passively. This extra resistor involves additional losses to the system. References [1] and [2] proposed analysis of selecting the value of the damping resistor resulting in minimizing losses and ensuring LCL-filter stability. In [3], different passive damping techniques have been evaluated by connecting the damping resistor in different locations in the LCL-filter. The active damping approach avoid losses introduced by the passive damping approaches however it adds more complexity to the system control. In [4], a tuning procedure of lead-lag network method for active damping in LCL-filter has been proposed. In [5], the power theory with PQR power transformation in order to compensate and improve the stability caused by the additional resonance poles caused by LC section of the LCL filter has been proposed. In [6], the active damping methods using a digital filter has been reviewed. Other approaches of active damping control strategies were investigated and analyzed in [7] where a twodegree-of-freedom (2DOF) allows the independent action of PID controller terms. The analysis of filter capacitor current and voltage was conducted in [8] and concluded that either the proportional feedback of the currents or derivative feedback on the voltages are required for system stability. The regulation of the injected grid current with the capacitor current and the filter-capacitor current feedback in order to actively damping the resonance introduced by the LC elements have been introduced in [9], [10], and [11] respectively.

A new topology of high-order passive filter (LLCL filter) consisting of adding a small inductor in series with the capacitor of the LCL-filter which yields to the LLCL-filter configuration shown in figure 1. The LLCL-filter presents a better attenuation of the switching-frequency harmonic current components than the LCL-filter therefore reducing the total size of the inductors. However, inverter-based distributed generation (IBDG) with LLCL-filter has to be well stabilized especially with the underdamped oscillations. Several passive and active damping techniques for the IBDG with LLCL filter have been investigated by researchers [15-21]. These damping methods consist of a combination of a damping resistor $\left(\boldsymbol{R}_{\boldsymbol{d}}\right)$, a damping inductor $\left(\boldsymbol{L}_{\boldsymbol{d}}\right)$, and a damping capacitor $\left(\boldsymbol{C}_{\boldsymbol{d}}\right)$ in series and/or in parallel to the shunt element $\left(\boldsymbol{L}_{f}, \boldsymbol{C}_{f}\right)$. Yet, an IBDG system integrating LLCL-filter require more complex control strategies. A passive damping technique for single-phase gridtied inverter [12] where a new passive damping structure with reduced power losses by introducing an optimized damping resistor value was proposed. In [13], it has been concluded that the additional small inductance in series with the capacitor branch attenuates the current ripples at the switching frequency, and it reduces the total inductance yielding a size reduction. In 
[14] and [15], another method of passive damping using RC as parallel circuit to the LC branch of the LLCL-filter and RL as a series circuit with the grid-side inductor has been proposed. In [16], a modified structure of the LLCL-filter has been proposed where a capacitor is connected in parallel to the LC branch to reduce the EMI noise. A damping technique that combines both digital filter and RC parallel damper that guarantees the stability of the LLCL filter while the grid inductor is varying, was discussed in [17]. In [18], a strategy that consists of splitting the elements of the LC branch into two sections then using the current flowing between these sections as feedback in order to stabilize the system has been proposed.

All of the previous contributions did not investigate the multiloop control strategy applied to stabilize the LLCL-filter. However, the control techniques such as multiloop [19], [20], and dual-loop [21] have presented analysis of these techniques on LCL-filter only. Therefore, a stability analysis of the LLCL filter-based grid-interfaced three-phase inverter using the multiloop control strategy with passive damping techniques will be presented as contribution through the current paper. This analysis considers the grid current $\left(\boldsymbol{i}_{g}\right)$ as the outer loop and observing the performance of the system with the capacitor voltage $\left(\boldsymbol{v}_{c}\right)$, capacitor current $\left(\boldsymbol{i}_{c}\right)$ or inverter-side inductor current $\left(\boldsymbol{i}_{L}\right)$ as the inner loop. A comparative study between a proportional-integral $(\boldsymbol{P I})$ and a proportional-resonant $(\boldsymbol{P R})$ is conducted and presented in this paper. The stability analysis was evaluated and assessed by simulation using root locus and bode plots in Matlab/Simulink.

\section{LCL and LLCL Filter Models}

In this section the LCL and LLCL filter models are presented and compared.

\section{A. LCL filter model}

The per-phase equivalent circuit of an LCL filter connecting the inverter to the grid is presented in figure 1. The LCL-filter consists the inverter-side inductor $\mathrm{L}_{\text {inv }}$, the grid-side inductor $\mathrm{L}_{\mathrm{g}}$, and the capacitor filter $\mathrm{C}_{\mathrm{f}}$.

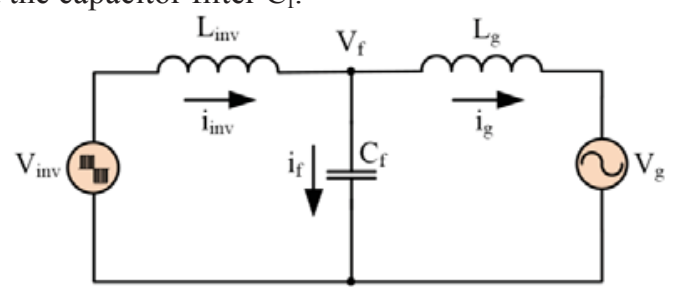

Figure 1. Per-phase equivalent circuit with LCL-filter

The open loop transfer functions $G_{1}(s)$ from input voltageinverter side $V_{\text {inv }}$ to output current-grid side $i_{g}$ and $G_{2}(s)$ from input voltage-inverter side $V_{\text {inv }}$ to input current-inverter side $i_{\text {inv }}$ can be respectively represented as per the following:

$$
G_{1}(s)=\frac{i_{g}(s)}{V_{i n v}(s)}=\frac{1}{L_{i n v} L_{g} C_{f} s^{3}+\left(L_{i n v}+L_{g}\right) s}
$$

$$
G_{2}(s)=\frac{i_{i n v}(s)}{V_{i n v}(s)}=\frac{L_{g} C_{f} s^{2}+1}{L_{i n v} L_{g} C_{f} s^{3}+\left(L_{i n v}+L_{g}\right) s}
$$

\section{B. LLCL Filter Model}

The LLCL-filter consists of the inverter-side inductor $\mathrm{L}_{\text {inv }}$, the grid-side inductor $\mathrm{L}_{\mathrm{g}}$, and a shunt element containing the filter inductance $\mathrm{L}_{\mathrm{f}}$ connected in series with the capacitor filter $\mathrm{C}_{\mathrm{f}}$. The per-phase equivalent circuit is shown in figure 2 .

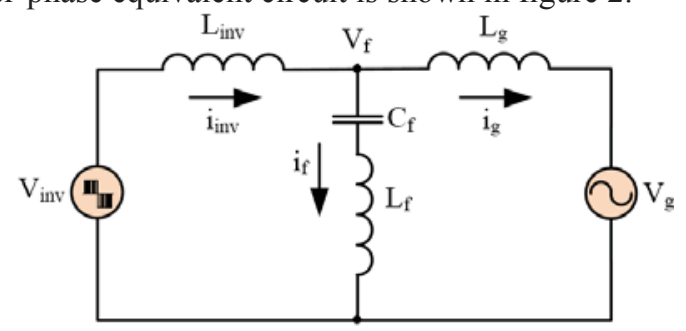

Figure 2. Per-phase equivalent circuit with LLCL-filter

The open loop transfer functions $\mathrm{G}_{3}(\mathrm{~s})$ from input voltageinverter side $V_{\text {inv }}$ to output current-grid side $i_{g}$ and $G_{4}(s)$ from input voltage-inverter side $V_{\text {inv }}$ to input current-inverter side $i_{\text {inv }}$ can be respectively represented by (3) and (4).

$$
\begin{gathered}
G_{3}(s)=\frac{L_{f} C_{f} s^{2}+1}{\left(L_{g} L_{f}+L_{i n v}\left(L_{g}+L_{f}\right)\right) C_{f} s^{3}+\left(L_{i n v}+L_{g}\right) s} \\
G_{4}(s)=\frac{\left(L_{g}+L_{f}\right) C_{f} s^{2}+1}{L_{i n v}\left(L_{g}+L_{f}\right) C_{f} s^{3}+L_{g} L_{f} C_{f} s^{2}+\left(L_{i n v}+L_{g}\right) s}
\end{gathered}
$$

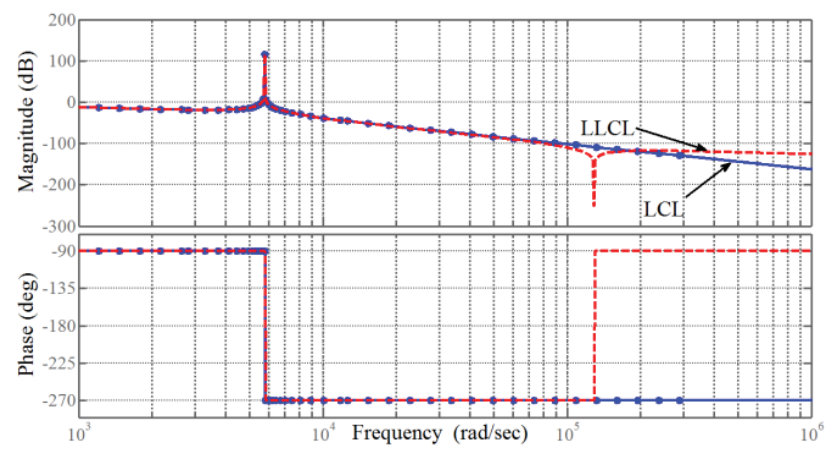

(a)

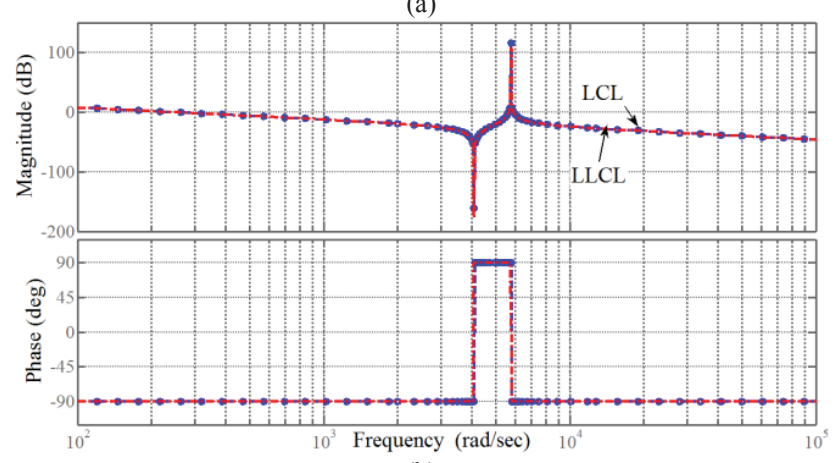

(b)

Figure 3. Bode Plot of Transfer Function for LCL and LLCL-Filters (a) $\mathrm{i}_{\mathrm{g}}(\mathrm{s}) / \mathrm{V}_{\text {inv }}(\mathrm{s})$ and $(\mathrm{b}) \mathrm{i}_{\text {inv }}(\mathrm{s}) / \mathrm{V}_{\text {inv }}(\mathrm{s})$ 
As it can be seen from figure $3 a$ that the LCL and LLCL filters have the same frequency response. However, at the switching frequency $20 \mathrm{kHz}(125 \mathrm{krad} / \mathrm{sec})$, the LLCL filter offers a better attenuation than LCL filter. Figure $3 b$ illustrates the frequency response for transfer function from input $V_{\text {inv }}$ to the output $i_{\text {inv }}$ where it is clear that the addition of the inductor in series with the filter capacitor of the LLCL filter, does not change the behavior of the LCL filter for all frequencies.

\begin{tabular}{|l|l|c|l|}
\hline \multicolumn{4}{|c|}{ LLCL Filter Parameters } \\
\hline$L_{i n v}$ & Filter inductor - Inverter side & $\mathbf{2 . 0}$ & {$[\mathrm{mH}]$} \\
\hline$L_{g}$ & Filter inductor - Grid side & $\mathbf{2 . 0}$ & {$[\mathrm{mH}]$} \\
\hline$L_{f}$ & Filter inductor - Parallel Branch & $\mathbf{2 . 0}$ & {$[\mu \mathrm{H}]$} \\
\hline$C_{f}$ & Filter capacitor - Parallel Branch & $\mathbf{3 0}$ & {$[\mu \mathrm{F}]$} \\
\hline$R_{d}$ & Damping resistor - Parallel Branch & $\mathbf{2 . 0}$ & {$[\Omega]$} \\
\hline$C_{d}$ & Damping Capacitor - Parallel Branch & $\mathbf{2 0}$ & {$[\mu \mathrm{F}]$} \\
\hline$f_{s w}$ & Switching Frequency & $\mathbf{2 0}$ & {$[\mathrm{kHz}]$} \\
\hline \multicolumn{2}{|c|}{ Controller Parameters } & $\mathbf{0 . 1 ~ - 1}$ \\
\hline$K_{p}$ & Proportional gain (PI) & $\mathbf{0 . 1}-\mathbf{1}$ \\
\hline$K_{i}$ & Integral (PI) & $\mathbf{0 . 1}-\mathbf{1}$ \\
\hline$K_{p}$ & Proportional gain (PR) & $\mathbf{0 . 1}-\mathbf{1}$ \\
\hline$K_{i}$ & Integral (PR) & $\mathbf{1}$ \\
\hline$K$ & PWM modulator (gain) &
\end{tabular}

Table I: LLCL-Filter and Control - Simulation Parameters

\section{LLCL Filter Control Analysis}

The block diagram illustrated in figure 4 shows the LLCL-filter with PI and PR controllers. The transfer function for the PI controller is given in (5) and for the PR controller in (6).

$$
\begin{gathered}
G_{P I}(s)=K_{p}+\frac{K_{i}}{s} \\
G_{P R}(s)=K_{p}+K_{i} \frac{s}{s^{2}+\omega^{2}}
\end{gathered}
$$

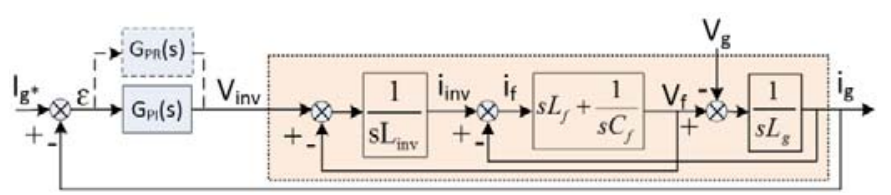

Figure 4. Block Diagram LLCL-Filter with PI and PR Controllers

The LLCL-filter parameters as well as the parameters of the PI and PR controllers which are used for simulation are listed in table I. The first simulation results obtained on the LLCL-filter without passive damping elements are shown in figure 3 . The frequency response of the open loop transfer functions given in (7) and (8), that represents the grid current with respect to the error between the reference current and the feedback current, are illustrated in figure 5.

$$
G_{1}(s)=\frac{i_{g}(s)}{\varepsilon(s)}=\frac{n_{3} s^{3}+n_{2} s^{2}+n_{1} s+n_{0}}{d_{4} s^{4}+d_{3} s^{3}+d_{2} s^{2}+d_{1} s+d_{0}}
$$

$n_{3}=K_{p} L_{f} C_{f} ; n_{2}=K_{i} L_{f} C_{f} ; n_{1}=K_{p} ; n_{0}=K_{i}$

$d_{4}=\left(L_{i n v}\left(L_{g}+L_{f}\right)+L_{g} L_{f}\right) C_{f} ; d_{3}=0$

$d_{2}=\left(L_{i n v}+L_{g}\right) ; d_{1}=0 ; d_{0}=0$

$$
\begin{aligned}
& G_{2}(s)=\frac{i_{g}(s)}{\varepsilon(s)}=\frac{n_{4} s^{4}+n_{3} s^{3}+n_{2} s^{2}+n_{1} s+n_{0}}{d_{5} s^{5}+d_{4} s^{4}+d_{3} s^{3}+d_{2} s^{2}+d_{1} s+d_{0}} \\
& n_{4}=K_{p} L_{f} C_{f} ; n_{3}=K_{i} L_{f} C_{f} ; n_{2}=K_{p}\left(\omega_{r}^{2} L_{f} C_{f}+1\right) \\
& n_{1}=K_{i} ; n_{0}=K_{p} \omega_{r}^{2} \\
& d_{5}=\left(L_{i n v}\left(L_{g}+L_{f}\right)+L_{g} L_{f}\right) C_{f} ; d_{4}=0 \\
& d_{3}=\left(L_{i n v}\left(L_{g}+L_{f}\right)+L_{g} L_{f}\right) C_{f} \omega_{r}^{2}+\left(L_{i n v}+L_{g}\right) \\
& d_{2}=0 ; d_{1}=\left(L_{i n v}+L_{g}\right) \omega_{r}^{2} ; d_{0}=0
\end{aligned}
$$

The LLCL-filter presents the same behavior in terms of amplitude with both controllers Proportional Integral and Proportional Resonant at the resonant frequencies $\omega_{1}$ and $\omega_{2}$. The expressions for $\omega_{1}$ and $\omega_{2}$ are given respectively in (9) and (10).

$$
\begin{gathered}
\omega_{1}=\frac{1}{\sqrt{\left(\left(\frac{L_{i n v} L_{g}}{L_{i n v}+L_{g}}\right)+L_{f}\right) C_{f}}} \\
\omega_{2}=\frac{1}{\sqrt{L_{f} C_{f}}}
\end{gathered}
$$

With both controllers (PI \& PR), The LLCL-filter presents the same magnitude response among all frequencies. However, it has opposite phase $\left(180^{\circ}\right)$ between the resonant frequencies $\omega_{1}$ and $\omega_{2}$ as illustrated by the phase diagram in figure 5 .

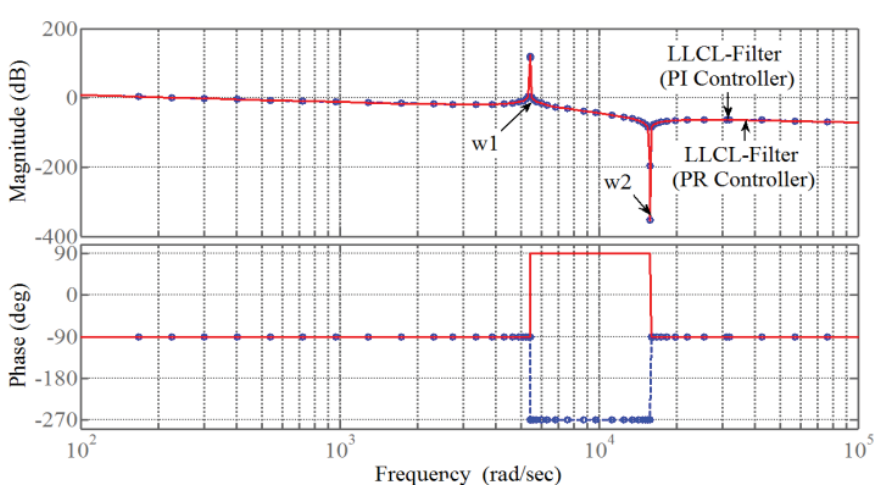

Figure 5. Open Loop Transfer Function LLCL-Filter with PI \& PR Controllers

\section{Passively-Damped LLCL-Filter}

Figure 6 shows the first structure of LLCL filter with passive damping circuit. It consists of series $R_{d}$ and $C_{d}$ connected in parallel to a series circuit of $\mathrm{L}_{\mathrm{f}}$ and $\mathrm{C}_{\mathrm{f}}$. The block diagram 
representing the circuit in figure 6 is illustrated in figure 7 . The bode plot for the open loop transfer function of the block diagram is shown in figure 8 where it is clear that with both PI controller and PR controller attenuate harmonics of high frequency by $-60 \mathrm{~dB} /$ decade while with $\mathrm{PR}$ controller, the system has more gain margin.

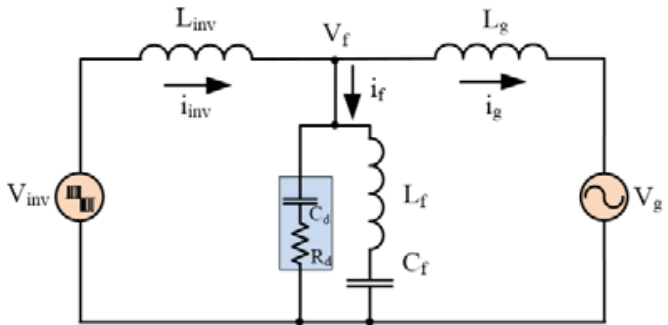

Figure 6. LLCL-Filter with Passive Damping $\left(\mathrm{R}_{\mathrm{d}}\right.$ and $\left.\mathrm{C}_{\mathrm{d}}\right)$

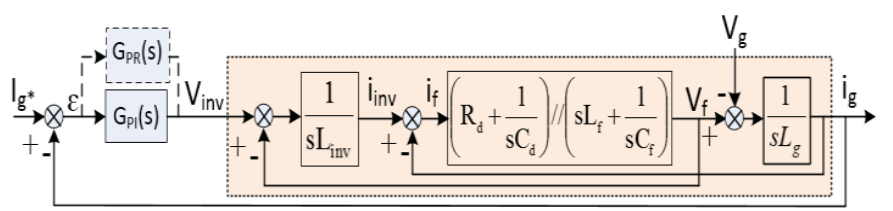

Figure 7. Block Diagram of the LLCL-Filter with Passive Damping $\left(\mathrm{R}_{\mathrm{d}} \& \mathrm{C}_{\mathrm{d}}\right)$

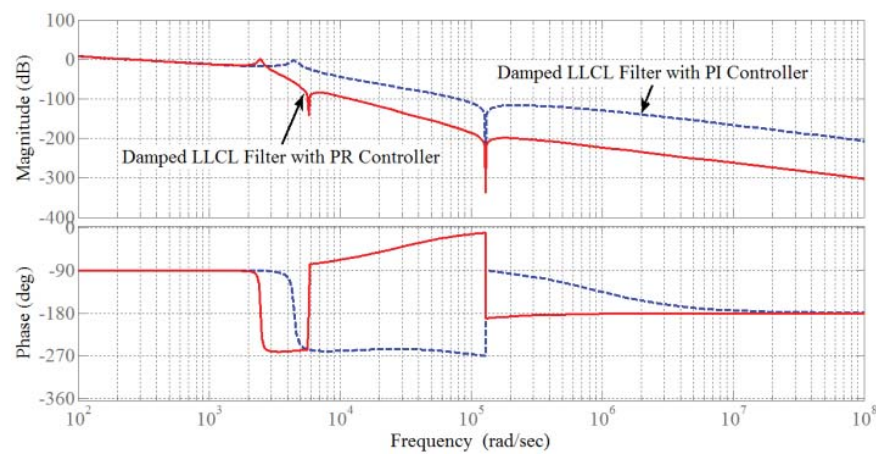

Figure 8. LLCL-Filter with Passive Damping $\left(\mathrm{R}_{d}\right.$ and $\left.\mathrm{C}_{\mathrm{d}}\right)$ with PI\&PR Controllers

The bode plot of the open loop transfer function of the LLCL filter as presented in figure 6 with the proportional-integral (PI) and the proportional-resonant (PR) controllers is illustrated in figure 8 . The open loop transfer function presents three cut-off frequencies with PR controller.. As shown in figure 8, the PR controller presents more gain margin than PI controller.

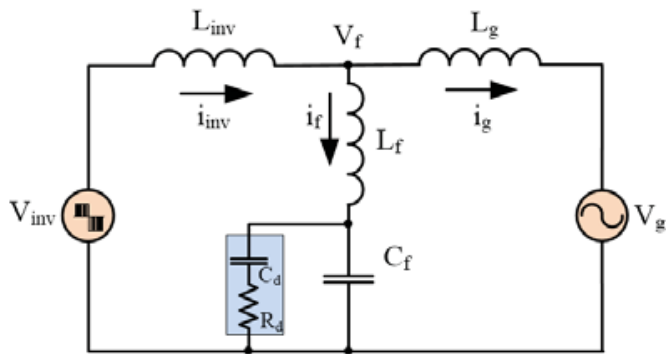

Figure 9. LLCL-Filter with Passive Damping $\left(\mathrm{R}_{\mathrm{d}}\right.$ and $\left.\mathrm{C}_{\mathrm{d}}\right)$ Parallel to $\mathrm{Cf}$

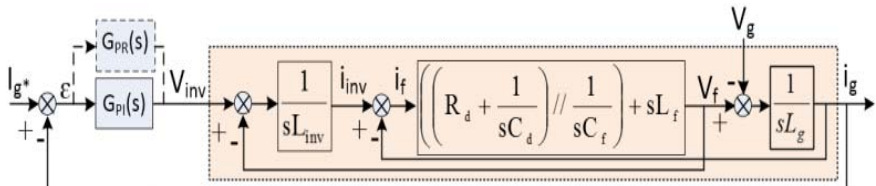

Figure 10. Block Diagram of the LLCL-Filter with Passive Damping $\left(\mathrm{R}_{\mathrm{d}} \& \mathrm{C}_{\mathrm{d}}\right)$

For the other case where the damping circuit is connected in parallel to $\mathrm{C}_{\mathrm{f}}$ only as illustrated in figure 9 , the high frequency harmonics are attenuated with the same maner in the presence of the PI and PR controllers. The bode plot in figure 11 demonstrates the behavior of the PI and PR controllers on the high-frequency harmonics for the open loop transfer function for the block diagram illustrated in figure 10 .

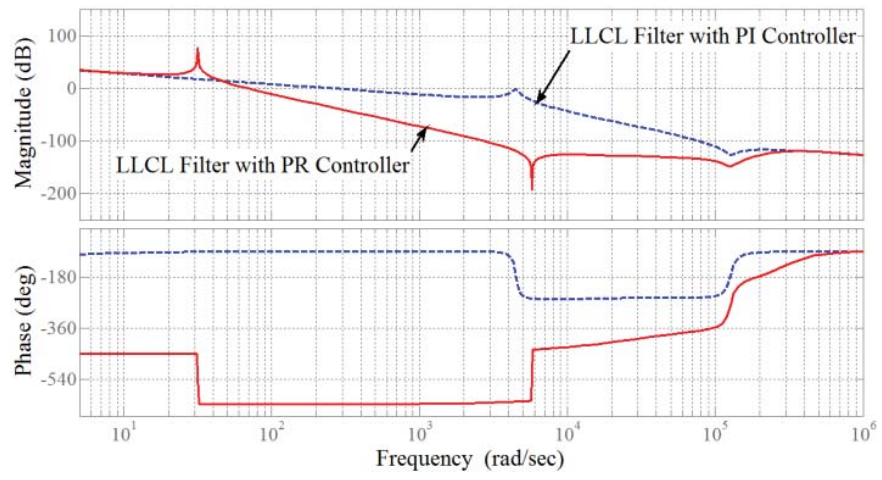

Figure 11. LLCL-Filter with Passive Damping $\left(\mathrm{R}_{\mathrm{d}}\right.$ and $\left.\mathrm{C}_{\mathrm{d}}\right)$ Parallel to $\mathrm{C}_{\mathrm{f}}$ with PI \& PR Controller

\section{Stability Analysis}

Similar to the LCL filter, the LLCL is a high power filter therefore it requires a damping circuit. In this section, the passive damping technique is investigated through three inner loops. In [19], the analysis of six state variables $u_{1}, i_{1}, u_{c}, i_{c}, u_{2}$, and $i_{2}$ in the LCL filter which can be adopted to damp the resonance has been presneted. According to the stability results achieved by [19], three of the proposed variable feedback parameters to damp the resonance effect will be analysed in the current paper for the LLCL filter. Figure 12 shows the block diagram of the LLCL filter with the three inner loops (The diagram shows the three inner loops together, but they are used separately) such as the Inverter-side inductor current $\mathbf{i}_{\text {inv }}$, capacitor current $\mathbf{i}_{\mathbf{c}}$, and capacitor voltage $\mathbf{v}_{\mathbf{c}}$. The PWM inverter unit is simplified to the gain $\mathbf{K}_{\mathbf{P W M}}$ and it is considered to be a unity gain. For comparative study, the $\mathbf{P I}$ and $\mathbf{P R}$ controlles have been used independently for the outer feedback. The PI and $\mathbf{P R}$ parameters used during the simulation phase are presented in table I. In order to examine the behavior of each controller while the connection of the damping circuit $\boldsymbol{R}_{\boldsymbol{d}} \boldsymbol{C}_{\boldsymbol{d}}$ is relocated around the $\boldsymbol{L}_{\boldsymbol{f}} \boldsymbol{C}_{\boldsymbol{f}}$ parallel branch, the used parameters were fixed to the values stated in table I.

Figures 13a-c demonstrate the effect of the location of the damping circuit on the stability of the system as illustrated in figures 6 and 9. Also, the consequence of the inner loops and PR controller is shown, where it can be seen that $\boldsymbol{R}_{\boldsymbol{d}} \boldsymbol{C}_{\boldsymbol{d}}$ damping 
circuit connected in parallel to $\boldsymbol{L}_{f} \boldsymbol{C}_{\boldsymbol{f}}$ offers a better attenuation of the harmonics with high frequencies compared to its connection in parallel to $\boldsymbol{C}_{\boldsymbol{f}}$ only.

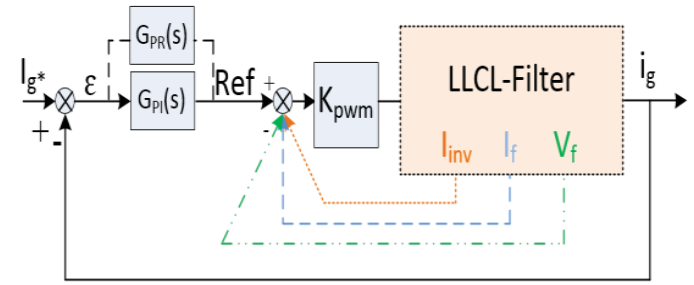

Figure 12. Block Diagram for Passive Damping with Inner Loops

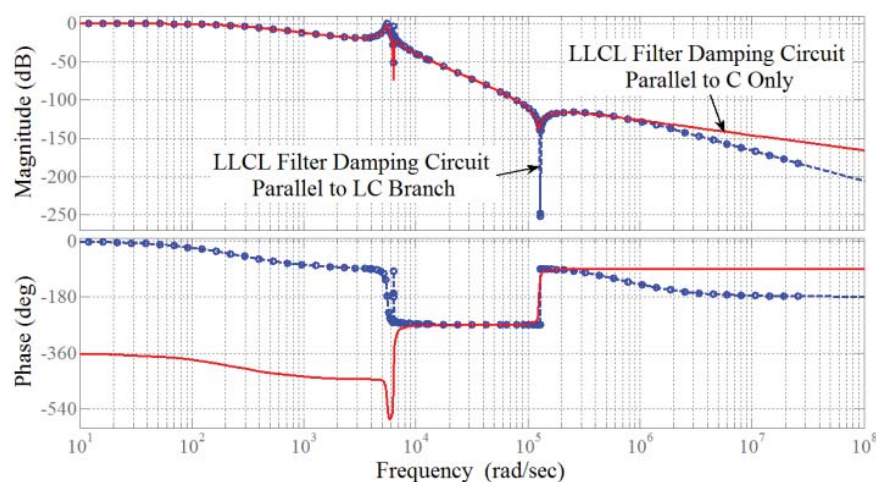

(a)

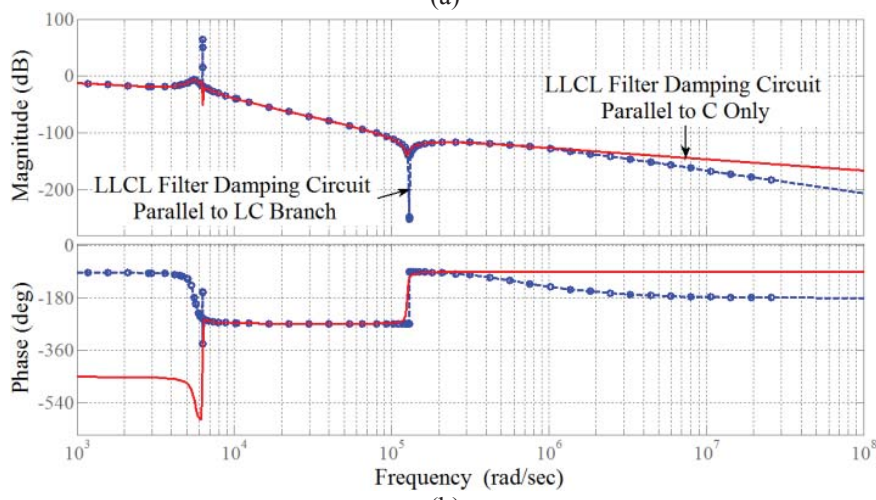

(b)

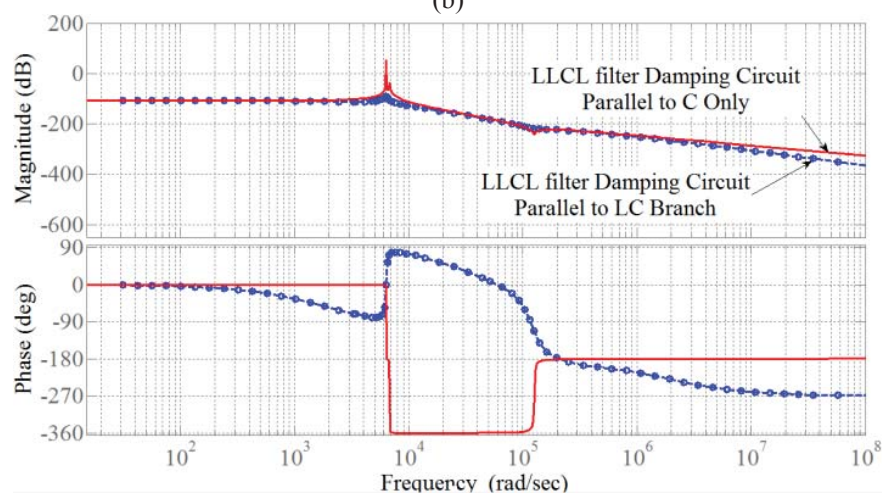

(c)

Figure 13. Bode Plot for Two Passive Damping Circuits with Inner Loops and PR Controller (a) Inverter-Side Inductor Current (b) Filter Parallel Branch Current (c) Filter Parallel Branch Voltage
The graphs displayed in figure 13a-c show the effect of the inverter-side inductor current as well as the current flowing through and the voltage across the parallel branch that includes the damping elements (resistor and capacitor) and the filter elements (capacitor and inductor) with the two studied configurations as shown in figures 6 and 9 using the PR controller on the system stability.

Based on the bode plots illustrated in figures 13a-c, the inverterside inductor current $\mathbf{i}_{\mathbf{L}}(\mathbf{s})$ and the current $\mathbf{i}_{\mathbf{f}}(\mathbf{s})$ flowing through the filter parallel branch offer an underdamping attenuation when a damping circuit $\left(\mathbf{R}_{\mathbf{d}}\right.$ and $\left.\mathbf{C}_{\mathbf{d}}\right)$ is connected in parallel to $\mathbf{L}_{\mathbf{f}}$ series with $\mathbf{C}_{\mathbf{f}}$ compared to the other configuration where the damping circuit $\left(\mathbf{R}_{\mathbf{d}}\right.$ and $\left.\mathbf{C}_{\mathbf{d}}\right)$ is mounted in parallel to the capacitor $\mathbf{C}_{\mathbf{f}}$ only. However, the first configuration offers a better harmonics attenuation for high frequencies. The voltage $\mathrm{V}_{\mathbf{f}}(\mathbf{s})$ across the parallel branch as inner loop with the configuration illustrated in figure 6 offer both advantages; overdamping with better harmonics attenuation compared to the configuration where the damping circuit is connected to the filter capacitor element only.

The selection of the damping circuit topology depends on the inner loop type. However, it can be seen that for better attenuation of the harmonics with considerable overdamping the LLCL filter with damping resistor $\mathbf{R}_{\mathbf{d}}$ and capacitor $\mathbf{C}_{\mathbf{d}}$ connected in series and attached in parallel to the inductor filter $\mathbf{L}_{\mathbf{f}}$ and the capacitor filter $\mathbf{C}_{\mathbf{f}}$ while considering the voltage across the filter parallel branch as inner loop would be the appropriate configuration.

\section{Conclusion}

A comparative study between the open loop transfer functions of the LCL filter and the LLCL filter was presented. It was concluded that for high frequencies, the LLCL filter offers a better attenuation than LCL filter. Another study was considered for the LLCL filter with existence of the PI then PR controllers. Also, it was determined that both controllers provide the same amount of attenuation. In this paper, two configurations of passively damped LLCL filter with PR controller only were examined by introducing the inverter-side inductor current, the current flowing through and the voltage across the filter branch as inner loop for the multi-loop stratergy. The obtained results show that among the two passively damped LLCL filter and between the three inner loops, the LLCL filter with $\mathbf{R}_{\mathbf{d}}$ series with $\mathbf{C}_{\mathbf{d}}$ and both parallel to $\mathbf{L}_{\mathbf{f}}$ series with $\mathbf{C}_{\mathbf{f}}$ configuration and the voltage across the filter branch inner loop demonstrate better attenuation with well overdamped amount which would be an appropriate structure.

\section{Acknowledgement}

This publication was made possible by NPRP grant [4 - 250 - 2 - 080] from the Qatar National Research Fund (a member of Qatar Foundation). The statements made herein are solely the responsibility of the authors 


\section{References}

[1] Peña-Alzola, R.; Liserre, M.; Blaabjerg, F.; Sebastián, R.; Dannehl, J.; Fuchs, F.W., "Analysis of the Passive Damping Losses in LCL-Filter-Based Grid Converters," Power Electronics, IEEE Transactions on , vol.28, no.6, pp.2642,2646, June 2013

[2] Balasubramanian, A.K.; John, V., "Analysis and design of split-capacitor resistiveinductive passive damping for LCL filters in grid-connected inverters," Power Electronics, IET, vol.6, no.9, pp.1822,1832, November 2013

[3] Ahmed, K.H.; Finney, S.J.; Williams, B.W., "Passive Filter Design for Three-Phase Inverter Interfacing in Distributed Generation," Compatibility in Power Electronics, 2007. CPE '07, vol., no., pp.1,9, May 29 2007-June 12007

[4] Pena-Alzola, R.; Liserre, M.; Blaabjerg, F.; Sebastian, R.; Dannehl, J.; Fuchs, F.W., "Systematic Design of the LeadLag Network Method for Active Damping in LCL-Filter Based Three Phase Converters," Industrial Informatics, IEEE Transactions on, vol.10, no.1, pp.43,52, Feb. 2014

[5] Hea-Gwang Jeong; Kyo-Beum Lee; Sewan Choi; Woojin Choi, "Performance Improvement of LCL-Filter-Based Grid-Connected Inverters Using PQR Power Transformation," Power Electronics, IEEE Transactions on , vol.25, no.5, pp.1320,1330, May 2010

[6] Dannehl, J.; Liserre, M.; Fuchs, F.W., "Filter-Based Active Damping of Voltage Source Converters With LCL Filter," Industrial Electronics, IEEE Transactions on , vol.58, no.8, pp.3623,3633, Aug. 2011

[7] Hanif, M.; Khadkikar, V.; Weidong Xiao; Kirtley, J.L., "Two Degrees of Freedom Active Damping Technique for LCL Filter-Based Grid Connected PV Systems," Industrial Electronics, IEEE Transactions on , vol.61, no.6, pp.2795,2803, June 2014

[8] Dannehl, J.; Fuchs, F.W.; Hansen, S.; Thøgersen, P.B., "Investigation of Active Damping Approaches for PIBased Current Control of Grid-Connected Pulse Width Modulation Converters With LCL Filters," Industry Applications, IEEE Transactions on , vol.46, no.4, pp.1509,1517, July-Aug. 2010

[9] Hedayati, M.H.; Acharya B, A.; John, V., "Common-Mode and Differential-Mode Active Damping for PWM Rectifiers," Power Electronics, IEEE Transactions on , vol.29, no.6, pp.3188,3200, June 2014

[10]Chenlei Bao; Xinbo Ruan; Xuehua Wang; Weiwei Li; Donghua Pan; Kailei Weng, "Step-by-Step Controller Design for LCL-Type Grid-Connected Inverter with Capacitor-Current-Feedback Active-Damping," Power Electronics, IEEE Transactions on, vol.29, no.3, pp.1239,1253, March 2014

[11]Pan, D.; Ruan, X.; Bao, C.; Li, W.; Wang, X., "CapacitorCurrent-Feedback Active Damping With Reduced Computation Delay for Improving Robustness of LCLType Grid-Connected Inverter," Power Electronics, IEEE Transactions on, vol.29, no.7, pp.3414,3427, July 2014
[12] Weimin Wu; Yuanbin He; Tianhao Tang; Blaabjerg, F., "A New Design Method for the Passive Damped LCL and LLCL Filter-Based Single-Phase Grid-Tied Inverter," Industrial Electronics, IEEE Transactions on , vol.60, no.10, pp.4339,4350, Oct. 2013

[13] Weimin Wu; Yuanbin He; Blaabjerg, F., "An LLCL Power Filter for Single-Phase Grid-Tied Inverter," Power Electronics, IEEE Transactions on , vol.27, no.2, pp.782,789, Feb. 2012

[14] Weimin Wu; Min Huang; Yunjie Sun; Xiongfei Wang; Blaabjerg, F., "A composite passive damping method of the LLCL-filter based grid-tied inverter," Power Electronics for Distributed Generation Systems (PEDG), 2012 3rd IEEE International Symposium on , vol., no., pp.759,766, 25-28 June 2012

[15] Wu, W.; Sun, Y.; Huang, M.; Wang, X.; Wang, H.; Blaabjerg, F.; Liserre, M.; Chung, H.S.-h., "A Robust Passive Damping Method for LLCL-Filter-Based GridTied Inverters to Minimize the Effect of Grid Harmonic Voltages," Power Electronics, IEEE Transactions on , vol.29, no.7, pp.3279,3289, July 2014

[16] Wu, W.; Sun, Y.; Lin, Z.; He, Y.; Huang, M.; Blaabjerg, F.; Chung, H.S.-h., "A Modified LLCL Filter With the Reduced Conducted EMI Noise," Power Electronics, IEEE Transactions on, vol.29, no.7, pp.3393,3402, July 2014

[17] Weimin Wu; Zhe Lin; Yunjie Sun; Xiongfei Wang; Min Huang; Huai Wang; Chung, H.S.-h., "A hybrid damping method for LLCL-filter based grid-tied inverter with a digital filter and an RC parallel passive damper," Energy Conversion Congress and Exposition (ECCE), 2013 IEEE, vol., no., pp.456,463, 15-19 Sept. 2013

[18] Wenjun Liu; Fei Liu; Jianjun Sun; Xiaoming Zha, "Current control for single-phase grid-connected inverters by splitting the elements of LLCL filter," Future Energy Electronics Conference (IFEEC), 2013 1st International, vol., no., pp.855,858, 3-6 Nov. 2013

[19] Poh Chiang Loh; Holmes, D.G., "Analysis of multiloop control strategies for LC/CL/LCL-filtered voltage-source and current-source inverters," Industry Applications, IEEE Transactions on , vol.41, no.2, pp.644,654, March-April 2005

[20] Poh Chiang Loh; Holmes, D.G., "Analysis of multi-loop control strategies for power conversion applications," Industry Applications Conference, 2003. 38th IAS Annual Meeting. Conference Record of the , vol.3, no., pp.1778,1785 vol.3, 12-16 Oct. 2003

[21] Wenqiang Zhao; Yuling Li; Guozhu Chen, "A double-loop current control strategy for Shunt Active Power Filter with LCL filter," Industrial Electronics, 2009. ISIE 2009. IEEE International Symposium on , vol., no., pp.1841,1845, 5-8 July 2009 